\title{
Health Workers'Experience on Directly Observed Treatment Short Courses Strategy to Stop TB Transmission in Khomas Redion, Namibia
}

\author{
Carolina Texeira ${ }^{1} \&$ Emmanuel Magesa ${ }^{1}$ \\ ${ }^{1}$ Clara Barton School of Nursing, Welwitchia Health Training Centre, Windhoek, Namibia \\ Correspondence: Emmanuel Magesa, Welwitchia Health Training Centre, 183 Industria Street, Lafrenz, \\ Windhoek, Namibia.Tel: +264-813-689-057. E-mail:emagesa2002@yahoo.com
}

Received: November 11, 2021 Accepted: January 19, 2022 Online Published: February 7, 2022

doi:10.5539/gjhs.v14n3p36

URL: https://doi.org/10.5539/gjhs.v14n3p36

\begin{abstract}
Background: Directly Observed Treatment short courses programme is the key strategy on national efforts to end the TB disease by 2035 . The aim of this study was to explore experiences of health care workers who care for patients receiving treatment under DOTS strategy at public health facilities in Windhoek, Namibia.

Methods: A qualitative explorative, descriptive research design was employed and a purposive sampling considering diversity was used to select participants who met the inclusion criteria for the study. A semi-structured interview guide was used to collect data. The study was conducted in the Windhoek district of the Khomas region, with a sample of 14 health care workers. Data was analysed by means of content analysis, a process of organizing and integrating narrative, qualitative data according to emerging themes and concepts.
\end{abstract}

Results: One theme emerged from data, which is the experiences of health care workers when attending to patients on DOTS. Participants shared their experiences on DOTS services and as result, shortage of staff, movements of patients from residential address, alcohol abuse and lack of enough food was repeatedly viewed as a barrier to DOTS services.

Conclusion: To achieve the goal of reduction of TB cases by $95 \%$ by 2030 , more training on the DOTS is needed for all health care workers.

Keywords: Directly Observed Treatment Short Course (DOTS), Experiences, Health Care Workers, qualitative research, Tuberculosis

\section{Introduction and Background}

Globally, estimated 10 million people fell ill and 1.5 million people died due to Tuberculosis (TB) in 2020, this makes TB a 13th leading cause of death and the second deadly infectious disease after COVID-19 (WHO, 2021). The largest number of new TB cases occurred in the South-East Asian Region, with 43\% of new cases, followed by the African Region, with 25\% of new cases and the last is Western Pacific with 18\% (Subbaraman, 2020). Despite recent progress in reducing the incidences and mortalities from TB, millions still suffer and die each year. Hence far from reaching global target as agreed at the UN high level meeting on TB (as cited Endjala et al., 2017).

In Sub Saharan Africa (SADC), it is estimated that, five deaths occur every hour due to TB (Falzon \& Raviglione, 2016). Namibia which is under SADC región is among the thirty high tuberculosis burden countries in the world, with 700 people estimated to have died as a result of TB in 2018 alone. The highest number was recorded in Khomas región, Namibia (Falzon \& Raviglione, 2016). However, according to 2020 TB report, Namibia has experienced a steady decline in the number of TB deaths by 7\% from 2019 to 2020 (as cited in Kigozi et al., 2016). Despite the decline of TB deaths in Namibia, more effort is needed as the target is to reduce TB deaths by 95 percent in 2035 (Mathema et al., 2017). Most of these deaths could be prevented with early diagnosis and appropriate treatment (Mathema et al., 2017). One of the key strategies to achieve 95\% reduction of TB deaths in the country, is to effectively implement the Directly Observed Treatment Short Course (DOTS) (Noé, 2017). Directly Observed Treatment Short Course is regarded as the best method to ensure full adherence and treatment success as the patient is psychological and morally supported throughout the treatment (Olaru, 2016).

This strategy is cost effective and has resulted in an estimated 10.1 million lives saved in the African region (Olaru, 2016). This strategy features the following five elements: Sustained political commitment to TB control, expressed in terms of adequate human and financial resources access to quality acquired network of sputum smear 
microscopy; Standardised short-course chemotherapy for all cases of TB under proper case management conditions, including directly observed treatment; Uninterrupted supply of quality assured anti-TB medicines. Recording and reporting system enabling treatment outcome, assessment of all patients and assessment of overall program performance (Serapelwane, 2016). The focus of this study is on healthcare worker's experiences of DOTS strategy in the Windhoek district, of the Khomas region. This study seeks to explore and to understand the problem in the Khomas Region's low treatment success rate of $83 \%$ among new smear-positive cases. The foregoing is still below the WHO's global target of 95\% success rate (WHO, 2020). One possible explanation for the above statistics could be attributed to heath care workers' inappropriate experiences which could contribute to low treatment and success experienced in the region. Therefore, the purpose of the study is to explore experiences of health care workers, specifically focus on health care workers who deal with TB patients on DOTS at public health facilities in Khomas Region. Such health workers Health care workers get first-hand experiences, as they spend a considerable amount of time with them. This is supported by a study conducted in by Shrestha (2017) on the nurses' roles and experiences with enhancing adherence to tuberculosis treatment among patients. The study indicated that nurses had experienced that most of the patients who were under their care on DOTS had followed well the schedules of their treatment. The study also indicated that indeed these nurses were at the forefront of TB care and that they play a critical role in informing about opportunities and obstacles to patients' adherence to TB treatment (Shrestha, 2017). The study further reveals that nurses' experienced that indiscipline among patients was also described as a reason for defaulting or incorrect treatment. Other study showed that health workers in TB clinic experience difficulties in handling TB patients due to complexity of TB such as Multidrug resistance and fluctuation in economy (Byberg et al., 2019). The patients do not listen to the nurses when they try to teach them about the disease and treatment, then they do not do as they were told (Shrestha, 2017; Serapelwane, 2016). Study done in South India, indicates that, the nurses believed that there was a difference among men and women regarding adherence to treatment as all nurses reported observing better adherence among women than men (Yellappa, 2016). This study also indicates that the experience by participants showed that TB patient with co-morbidity like HIV were struggling to follow the treatment compared to patients who suffered only from TB (Skinner, 2016). Finally, study done by Yusuf, et al. (2015) found that the experience of patients with TB and their care takers is indissolubly linked to their experience with DOTS. It was observed that having TB was not solely an individual patient's problem but, in most cases, a family issue. Some patients were found more vulnerable than others because of the relative level of poverty and social support they possessed.

\section{Design and Methods}

To explore the in-depth reality of experience of the health care workers who cares for the TB patients on DOT, a qualitative, phenomenological study design was employed to explore lived experiences of health workers on DOTS. This study design helps to describe experiences as they are lived and examines the uniqueness of individual health worker lived situations. In order to ensure credibility and to establish dependability inquiry audit was used, research process and data analysis was reviewed and examined to ensure that the findings are consistent and could be repeated and also the findings were base don participants response.

The population of interest was health care workers who work at TB clinic for not less than 6 months at Primary Health Care (PHC) facilities in Khomas region, Namibia. All PHC facilities in the region were included in the study, namely: Katutura Health Centre, Khomasdal Health Centre, Wanaheda Clinic, Okuryangava Health Centre, Otjomuise Clinic, Donkherhook Clinic, Hakahana Clinic and Robert Mugabe Clinic. Purposive sampling was used, as the researcher established a set of criteria to select participants who have experienced the phenomenon of interest and were able to describe those experiences.

\subsection{Procedure and Analysis}

A semi-structured interview guide with probing questions was used for data collection. The interviews were focused on the following aspects: Experiences of health care workers regarding DOTS services in the Windhoek district of the Khomas Region and how health workers deal with patients who miss their appointments for the DOTS. Data were collected due to diversity and saturation; hence, fourteen participants were interviewed. Prior to interview an informed consent to participate in the study was given to each participant. Data analysis was done by means of content analysis, a process of organizing and integrating narrative, qualitative data according to emerging themes and concepts. All interviews were transcribed verbatim and data analysis was based on the content of all the transcribed individual semi-structured interviews. Data analysis was adhered to the steps of content analysis (as cited in Leavy, P. 2017). These steps were as follows:

Step 1. Printed out transcripts, gathered notes, documents, or other materials.

Step 2. Read the data repeatedly to get a sense of what it contains. 
Step 3. Coded the data. In this case and organised the collected data by categorizing the images and texts; and then labelled the categories with a term.

Step 4. The reviewed of codes and combined them into themes.

Step 5. Advanced the way themes and descriptions were to be represented in the qualitative research.

Step 6. Marked interpretation of the findings.

One document was analysed at a time to determine the prevalence of any underlying information. The verbatim transcriptions from the audio recordings made during the interviews, as well as the notes taken during the same interviews, provided a record of the raw data. The data collected were stored electronically as audio recordings to use as a form of backup. The transcriptions and notes were stored as Microsoft Word files which were protected by a password to ensure security and confidentiality. Data from individual interviews were analysed by means of content analysis, a process of organizing and integrating narrative, qualitative data according to emerging themes and concepts. The following abbreviations were used: Tran $=$ Transcript, Par $=$ Participant and Pg $=$ Page, to be able to identify the origin of the verbatim quotations in the transcripts (page and transcript) as well as the participant's number.

\subsection{Ethical Approval}

The ethics committees of the Ministry of Health and Social Services (MoHSS), Khomas health Region Directorate and incharge of PHC facilities approved this study. The written informed was shared by the participants prior to data collection. Confidentiality of the participants was protected by the researcher whereby no names and site were recorded or noted down during the interviews, rather a coding system was always used.

\section{Findings}

\subsection{Description of the Participants}

The sample consisted of 14 health care workers who were working at Windhoek District Primary Health Care Centres and Clinics of the Khomas region. These health care workers consisted of 2 registered Nurses, 5 enrolled Nurses, 1 health assistant, and 6 community TB field promoters as indicated in Table 1.

Table 1. Demographic information of the Participants

\begin{tabular}{cllc}
\hline Participant & \multicolumn{1}{c}{ Gender } & \multicolumn{1}{c}{ Position } & Period of allocation \\
\hline P 1 & Female & Enrolled Nurse & 2 years \\
P 2 & Male & Health Assistant & 5 years \\
P 3 & Female & Enrolled Nurse & 1 year \\
P 4 & Female & TB Field Promoter & 7 months \\
P 5 & Female & TB Field Promoter & 7 Months \\
P 6 & Female & Enrolled Nurse & 1 Year \\
P 7 & Male & Enrolled Nurse & 3 Years \\
P 8 & Female & TB Field Promoter & 10 year \\
P 9 & Female & TB Field Promoter & 6 Months \\
P 10 & Female & TB field Promoter & 9 Months \\
P 11 & Female & Registered Nurse & 4 Years \\
P 12 & Female & Enrolled Nurse & 6 Months \\
P 13 & Female & TB Field Promoter & 11 Years \\
P 14 & Female & Registered Nurse & 5 Years \\
\hline
\end{tabular}

Participants in the study met the inclusion criteria to participate, which was to be a health care worker for a minimum of 6 months at the DOTS point. However, it was found that some participants were not trained on those guidelines or lacked some knowledge about them.

Only, one theme was emerged from the data analysis, that is experiences of health care workers when attending to 
the patients on DOTS strategy.

Table 2. Theme and Codes

\begin{tabular}{ll}
\hline Theme & Codes \\
\hline & 1.1.-Barriers to DOTS support-negative experiences \\
& 1.2.-Health education of difficult patients \\
Theme. The experiences of health care workers when & $\begin{array}{l}\text { 1.3.-Management of workload } \\
\text { attending to patients on the DOTS strategy. }\end{array}$ \\
& $\begin{array}{l}\text { 1.4.-Follow up of defaulters } \\
\text { 1.5.-Follow up of defaulters/recommendations } \\
\text { 1.6.-Language preferences } \\
\text { 1.7.-Convenient place for DOTS/ recommendations }\end{array}$ \\
\hline
\end{tabular}

\section{Theme. -The experiences of health care workers when attending to patients on DOTS.}

\section{Code 1.1.-Barriers to DOTS support-negative experiences}

Although some patients are fortunate enough to find good support during their treatment, others are not so lucky. Health care workers expressed that there are some barriers encountered by patients to DOTS support. One of these barriers, which were commonly identified, was too much movement of patients from one location to another and, in most instances, without the patients' informing their health care workers about their intentions to do so.

"The patients' movement in the Khomas region which is just too much even our percentage goes down because the patients are moving too much. It's like there are too many patients and it looks like we are managing them but it's just that a person will be diagnosed in Windhoek but then they go home to another city and won't come back anymore". (Tran 6 Par 6 Pg 7)

Other health workers experienced that; insufficient personnel allocated at DOTS points in the community constituted a barrier. Such lack of personnel provokes that patient have to wait for long periods of time before they can be attended to, discouraging them from going to the clinic for treatment.

"Currently the problem is that patients are a lot and not everyone can come for DOT and sometimes the patients a lost because of that but...maybe more health workers can be there for DOT. Currently there is no point in the locations in the community so everyone comes to the clinic, and not everyone can come to the clinic". (Tran 1 Par 1 Pg 2)

Nurses are particularly affected when there is a shortage of staff in the clinic they work at because, in those occasions, they are expected to help in other services that are also provided at the same clinic, leaving the DOTS point unattended. This situation constitutes a barrier to DOTS because, when patients come to the DOTS point and do not find the nurse there, they go back home thinking that there is no one to help them. This situation discourages the already exhausted patient to come back to the DOTS points to collect the treatment.

"There are difficulties like in this case in our work, it's a bit difficult because you are forever not in the TB room, you are assisting in the clinic doing screenings...so it will be a bit difficult to DOT your patients". (Tran 7 Par $7 \mathbf{P g}$ 7)

Code 1.2.-Health education of difficult patients.

Health care workers give health education to difficult patients to make them understand the importance of treatment adherence and the daily follow-up to take pills at the DOTS points. Health care workers said that they deal with a lot of patients who are difficult, but they usually make them understand the risks of not taking the medication. They also talk to family members of patients so that they too can help in making sure that the patients finish the course of their treatment.

"Yes, we have a lot of difficult patients, but what we do we go to their houses, and we have TB field promoters who go there. We go there and we give health education, continuous health education we talk to the family and the DOT supporter the family members so that they can understand what the risks are". (Tran 1 Par 1 Pg 3)

Health workers try to understand the patients' reasons as to why they missed some days without coming to take their medication. 
"Some of them are saying, "every day coming here, my legs are paining... the tablets are a lot... I cannot take them" but as a field promoter, you have to do health education-ongoing health education so that the patient can understand why he or she has to come every day to take his DOTS”. (Tran 8 Par $8 \mathbf{P g} 3$ )

Health education remains one of the most important and appropriate basic strategy through which enable people to increase control over, and to improve, their health.

\section{Code 1.3.-Management of workload}

Health care workers find some difficulties in managing the DOTS points due to the workload. Whenever there is a shortage of staff, they are expected to help with other duties in the same clinic. In some cases, nurses and TB field promoters have arrangements whereby, when the nurse is busy in the clinic and a patient comes, the TB field promoter goes and calls the nurse to attend to the patient.

"There is always communication between the field promoter and the nurse. Sometimes you make appointments to meet them and discuss about the patients. Otherwise, you can just contact each other through mobile telephones". (Tran 7 Par 7 Pg 7)

Despite these arrangements between nurses and TB field promoters in managing the workload, some nurses found it tiring to move up and down between the TB room and to the rest of the clinic.

"It is very difficult because you are removed from the room, you left there the patient while you are turning your back going to where you are going to help, there is a patient who is coming in and it irritates the patient when you tell them, please wait for a few minutes in about 30 minutes. That 30 minutes might turn into an hour or one and a half hours. You go back when you finish, help the patient and when you go back to help again another patient comes. It's very difficult". (Tran 11 Par 11 Pg 4)

\section{Code 1.4.-Follow up of defaulters}

When a patient does not come to the DOTS points for a certain period, health care workers follow up on them to find out what is the problem with the patient. Health care workers, especially the TB field promoters, go to the physical address of the patient and look for him/her. Sometimes they find them, but not always.

"I have to follow up and go to their house but there are things that are beyond our control. If I go and trace and I go there, I will only find the treatment supporter, but the patient is not there. Sometimes the patient is there, and we talk and try to solve the problem. If the patient is not there I will try to follow up". (Tran 4 Par 4 Pg 7)

Health workers also try to phone their patients, but some of them do not answer if they recognize that the number calling might be from the health care worker at the DOTS point.

"For the defaulter it's difficult because sometimes when you go to the house, you find the house is closed and you try also the number like if he defaulted, when he sees that number is calling, he can even not pick up the phone". (Tran 13 Par 13 Pg 6)

\section{Code 1.5.-Follow up of defaulters/recommendation}

To improve the treatment outcome of TB in the Windhoek district of the Khomas Region, health care workers involved on the treatment of TB patients need to put in extra efforts to make this journey as normal as possible, so that patients feel comfortable and free to express themselves on issues that affect their adherence to treatment. The following are some of the recommendations that health care workers made on what they think could assist in keeping patients on treatment without interruptions.

"Know your patients also. if you do not know your patients a patient can be lost to follow up and you will not even notice because you don't know them. So you should know very well your patients, know when they are supposed to come and record keeping is also very important". (Tran 1 Par 1 Pg 5)

Heath care workers also emphasised their recommendations on recognizing early enough that the patient did not come to take treatment, and not to wait until they become defaulters.

"If they don't come today and tomorrow, then I have to start to react today. I have to wonder, what happened to my patient, why is this person not coming? It is possible to know where this patient is staying because I can even take tablets to the person and even find out why this person did not come and drink these tablets". (Tran 8 Par 8 Pg 6)

The Ministry describes a TB patient who did not start treatment or whose treatment was interrupted for 2 consecutive months or more as "lost to follow up" (previously known as "defaulters). To minimise the default rate in the district, all health care workers involved in the care of TB patients need to be alert in recognizing patient who did not come after a few days, and not wait until a patient becomes defaulter as indicated in reporting system for 
Tuberculosis (WHO, 2016).

\section{Code 1.6.-Language preferences}

On their daily engagement with patients on DOTS, health care workers experienced that some patients prefer being spoken to in their mother languages for them to better understand what is being explained to them.

"Previously before I come in there was Mr...and he was Herero speaking, sometimes patients prefer him because of the language issue so that they can talk in Otjiherero". (Tran 1 Par 1 Pg 5)

"Most of the time, we focus on too much on health education, sometimes we are giving health education to someone who cannot understand the language. And then also, you must be very much smart on that. So, if you see that there is patient who is not very good in that language, you have to look for someone related to that person to come, or who knows that language". (Tran 2 Par 2 Pg 6)

Namibia is a multicultural country with different ethnic groups, each of them speaking their own mother language. On many occasions, health care workers treat patients who do not understand the official language and who might not speak same mother language. This creates a barrier in communication. In this situation, the best solution is to find someone to translate the information which is being conveyed to the patient and vice versa.

\section{Code 1.7.-Convenient place for DOTS / recommandation.}

Health care workers expressed their views on the convenient place for the patients to receive treatment under DOTS. For patients to successfully complete their treatment and be cured, some health care workers prefer that DOTS should be given at the clinic.

"Like, for the successfully cured, I want my patient to take the medication here, so I can observe when they are drinking because if I give them to take home, I don't know if they are really swallowing it. They just say they are swallowing but they didn't. Especially those who are staying alone". (Tran 5 Par 5 Pg 5)

Other health care workers think that the convenience of DOTS should be in the community because community leaders can work together with the health workers who are at those DOTS points.

"Sometimes it's convenient in the community. We can have the community leaders. The community leaders work together with us because as a community leader he knows that this patient of mine is taking TB treatment so I can even take the responsibility of my community TB patient so that we cannot have a lot of TB spreading in our community". (Tran 8 Par 8 Pg 9)

It is recommending that DOTS be provided at health facilities that are situated conveniently close to the patient's home or on his way to work. The patient takes the medicines every day under observation by the health care worker, except on weekends when the patient will take his/her anti-TB medicines at home. Other options to DOTS are community-based DOT, workplace DOT, guardian-based DOT, and community health worker-assisted DOT (United States Agency for International Development 2016).

The study found that, participants shared their experiences on DOTS services and as result, shortage of staff, movements of patients from residential address, alcohol abuse and lack of enough food was repeatedly viewed as a barrier to DOTS services.

\section{Discussion}

The findings of the study revealed that patients in Windhoek were very mobile. This means that patients changed home addresses very often according to the availability of work opportunities. This was reported as one of the reasons why patients were defaulting treatment at one particular DOTS point, since they did not inform their health care workers in advance that they were moving out of that area. This finding is supported by the study done in Papua Province in Indonesia, which indicates that moving residence is one of the factors contribute to poor DOTS adherence (Ruru et al., 2018). This gives the impression that patients are defaulting while, in reality they are taking their medications at another DOTS point, near to their new residential place. Also, it was found that health care workers experience difficulties in rendering good services to patients due to shortage of staff. This finding is supported by a study conducted in the Northwest Province, South Africa, by Serapelwane (2016). In that study, it was found that the shortage of staff was a major barrier to DOTS, due to the increase in workloads. Therefore, health workers had difficulties in executing their daily tasks in managing the health services for TB patients (Serapelwane, 2016). This situation increased the level of stress on the health care workers, which consequently resulted in burnout, with some staff taking decisions to resign. Consequently, this situation may result in poor services rendered to the patients, and it was even worse because there was also an increase in the number of patients who needed the services (WHO, 2017). Staff shortage creates a burden on health care workers hence 
patients need to wait a little longer before getting the service. This may frustrate TB patients and compromise adherence as supported in the study done by Skinner and Claassens (2016). It is found that health workers are experiencing some challenges regarding tracing defaulters, which was also mentioned in one study conducted in Ethiopia (Yusuf et al., 2015). Interrupting treatment may lead to drug resistance. Therefore, it is very important that TB field promoters, in collaboration with TB nurses and other health workers, identify those patients who are lost to follow up and establish the barriers for taking the treatment. At this point, the dangers of interrupting treatment, must be explained to the patients and then, together with the DOT supporter, take all the necessary measures to overcome barriers. Working out with the patient and his/her family members or DOT supporter is the best way to avoid interruption of the treatment after the visit (WHO, 2020). At times, when the health care worker needed to give health education and the patient did not understand the language; the health care worker had to arrange for someone to help translate the information that the patient needed to get, the issue of language was also indicated in the study which was conducted in Nepal (Shrestha et al., 2017). The health care workers reported that there are not enough DOTS points located in the communities. Therefore, DOTS points at the clinics are often overcrowded, and that this situation discourages some patients to go for their treatment as they believe that the locations of the DOTS points are far from their homes. Alcohol and lack of food was reported by health care workers as contributing factors for the patients to miss their appointments at the DOTS points because they simply forget about it because of alcohol and they said that, on their experience in working with DOTS, patients who had no food complained that they could not take the pills in an empty stomach as this would make them feel sick. These factors were also mentioned in the study conducted by Zhang, et al 2016. TB field promoters reported that when they trace down patients in the location, these patients tend to be arrogant and sometimes aggressive to them if it is found that the patients had been taking alcohol. The study found that, record keeping is a problem to the TB focal nurse: When the usual nurse is on vacation or off-duty, the relieving health care worker did not keep good records of what he/she had given and done to the patients. This created an impression that patients missed appointments while it was just poor record-keeping on the part of the health care workers.

\subsection{Limitation}

This study was conducted in one region in Namibia; therefore, the findings cannot be generalized as the true reflection of DOTS health care workers in the country.

\section{Conclusion}

To achieve the goal of reduction of TB cases by $95 \%$ by 2030 , holistic approach is needed, this includes training health care workers on the DOTS strategy, improving documentation and public awareness campaign on TB and its treatment.

\section{Competing Interests Statement}

The authors declare that there are no competing or potential conflicts of interest.

\section{References}

Adebanjo, O. D., \& Malangu, N. (2015). Knowledge and practices about multidrug-resistant tuberculosis amongst healthcare workers in Maseru. African Journal of Primary Health Care and Family Medicine, 7(1), 1-5. https://doi.org/10.4102/phcfm.v7i1.774

Byberg, L., Väster, K., Lepp, M., \& Rosengren, K. (2019) Nurses' Experiences of Caring for Patients with Tuberculosis - An Interview Study in Indonesia. Int Arch Nurs Health Care, 5, 136. doi.org/10.23937/2469-5823/1510136

Dlwati, L. V., Mavundla, T. R., \& Mbengo, F. (2017). Facilitators for and barriers to the implementation of national tuberculosis management guidelines. Africa Journal of Nursing and Midwifery, 19(3), 20-pages. https://doi.org/10.25159/2520-5293/2862

Endjala, T., Mohamed, S., \& Ashipala, D. O. (2017). Factors that contribute to treatment defaulting amongst tuberculosis patients in Windhoek District, Namibia. Clinical Nursing Studies, 5(4), 12. https://doi.org/10.5430/cns.v5n4p12

Falzon, D., \& Raviglione, M. (2016). The Internet of Things to come: digital technologies and the End TB Strategy. BMJ global health, 1(2), e000038. https://doi.org/10.1136/bmjgh-2016-000038

Kigozi, G., Heunis, C., Chikobvu, P., Botha, S., \& Van Rensburg, D. (2017). Factors influencing treatment default among tuberculosis patients in a high burden province of South Africa. International Journal of Infectious Diseases, 54, 95-102. https://doi.org/101016/j.ijid.2016.11.407. 
Leavy, P. (2017). Research design: Quantitative, qualitative, mixed methods, arts-based, and community-based participatory research approaches. New York: The Guiford Press.

Mathema, B., Andrews, J. R., Cohen, T., Borgdorff, M. W., Behr, M., Glynn, J. R., ... \& Wood, R. (2017). Drivers of tuberculosis transmission. The Journal of infectious diseases, 216(suppl_6), S644-S653. https://doi.org/10.1093/infdis/jix354

Noé, A., Ribeiro, R. M., Anselmo, R., Maixenchs, M., Sitole, L., Munguambe, K., ... \& García-Basteiro, A. L. (2017). Knowledge, attitudes and practices regarding tuberculosis care among health workers in Southern Mozambique. BMC pulmonary medicine, 17(1), 1-7. https://doi.org/10.1186/s12890-016-0344-8

Olaru, I. D., Lange, C., Indra, A., Meidlinger, L., Huhulescu, S., \& Rumetshofer, R. (2016). High rates of treatment success in pulmonary multidrug-resistant tuberculosis by individually tailored treatment regimens. Annals of the American Thoracic Society, 13(8), 1271-1278. https://doi.org/10.1513/AnnalsATS.201512-845OC

Polit, D. F., \& Beck, C. T. (2008). Nursing research: Generating and assessing evidence for nursing practice. Lippincott Williams \& Wilkins.

Republic of Namibia Ministry of Health and Social Services. (2010). National Strategic Plan on Tuberculosis (TB). Medium-Term Plan II (MTP-II): 2010-2015. Windhoek.

Ruru, Y., Matasik, M., Oktavian, A., Senyorita, R., Mirino, Y., Tarigan, L. H., ... \& Alisjahbana, B. (2018). Factors associated with non-adherence during tuberculosis treatment among patients treated with DOTS strategy in Jayapura, Papua Province, Indonesia. Global health action, 11(1), 1510592. https://doi.org/10.1080/16549716.2018.1510592

Serapelwane, M. G., Davhana-Maselesele, M., \& Masilo, G. M. (2016). Experiences of patients having tuberculosis (TB) regarding the use of directly observed treatment short-course (DOTS) in the North West Province, South Africa. Curationis, 39(1), 1-9. https://doi.org/10.4102/curationis.v39i1.1629

Shrestha, A., Bhattarai, D., Thapa, B., Basel, P., \& Wagle, R. R. (2017). Health care workers' knowledge, attitudes and practices on tuberculosis infection control, Nepal. BMC infectious diseases, 17(1), 1-7. https://doi.org/10.1186/s12879-017-2828-4

Skinner, D., \& Claassens, M. (2016). It's complicated: why do tuberculosis patients not initiate or stay adherent to treatment? A qualitative study from South Africa. BMC infectious diseases, 16(1), 1-9. https://doi.org/10.1186/s12879-016-2054-5

South Africa National Aids Council. (2016). South African HIV and TB Investment Case Summary Report Phase 1. March 2016. Pretoria: South Africa National Aids Council.

Subbaraman, R., Jhaveri, T., \& Nathavitharana, R. R. (2020). Closing gaps in the tuberculosis care cascade: an action-oriented research agenda. Journal of clinical tuberculosis and other mycobacterial diseases, 19, 100144. https://doi.org/10.1016/j.jctube.2020.100144

United States Agency for International Development. (2016). Committed to End TB. Tuberculosis Report to Congress. Washinton D.C. $\quad$ Retrieved from https://www.usaid.gov/sites/default/files/documents/1864/USAID-TB-ARTC-2018-508.pdf

World Health Organization [WHO]. (2015). Global Tuberculosis Report. Geneva. Retrieved from http://apps.who.int/iris/bitstream/10665/191102/1/9789241565059_eng.pdf

World Health Organization [WHO]. (2016). Global Tuberculosis Report. Geneva. Retrieved from http://apps.who.int/iris/bitstream/10665/250441/1/9789241565394-eng.pdf

World Health Organization [WHO]. (2017a). Global Tuberculosis Report. Geneva.

World Health Organization [WHO]. (2017b). The End TB Strategy. Global strategy and targets for tuberculosis prevention, care, and control.; Geneva. Retrieved from http://www.who.int/tb/strategy/End_TB_Strategy.pdf?ua=1

World Health Organization [WHO]. (2021). Framework for implementing the "End TB Strategy" in the world. Geneva.

Yellappa, V., Lefèvre, P., Battaglioli, T., Narayanan, D., \& Van der Stuyft, P. (2016). Coping with tuberculosis and directly observed treatment: a qualitative study among patients from South India. BMC health services research, 16(1), 1-11. https://doi.org/10.1186/s12913-016-1545-9

Yusuf, K. O., Seifu, M. F., Gelaw, B. K., Gebremariam, E. T., \& Mohammed, M. (2015). Non Adherence and its 
Contributing Factors to Anti-TB Drug in Childrenâ€ s at Adama Referral Hospital, Oromia, Ethiopia. Global Journal of Medical Research, 15(2). . Retrieved from https://globaljournals.org/GJMR_Volume15/3-Non-Adherence-and-its-Contributing.pdf

Zhang, H., Ehiri, J., Yang, H., Tang, S., \& Li, Y. (2016). Impact of community-based DOT on tuberculosis treatment outcomes: a systematic review and meta-analysis. PloS one, 11(2), e0147744. https://doi.org/10.1371/journal.pone.0147744

\section{Copyrights}

Copyright for this article is retained by the author(s), with first publication rights granted to the journal.

This is an open-access article distributed under the terms and conditions of the Creative Commons Attribution license (http://creativecommons.org/licenses/by/4.0/). 